Part of Journal of Research of the National Bureau of Standards, Volume 13, October 1934

\title{
PROPERTIES OF GRAY CAST IRON AS AFFECTED BY CASTING CONDITIONS
}

\author{
By C. M. Saeger, Jr., and E. J. Ash
}

\section{ABSTRACT}

A report of a preliminary investigation to determine the effect of maximum heating temperatures on the physical properties of different types of cast iron is given in this paper. It describes the methods and results obtained in a study of three types of cast iron. Four heats, all melted in a high-frequency induction furnace, were made for each type of iron with maximum heating temperatures of $1,400,1,500,1,600$, and $1,700^{\circ} \mathrm{C}$, respectively. Four pairs of transverse test bars, each pair of a given diameter, were cast from each heat in a dry-sand mold and the following properties were determined: Transverse breaking load, deflection, modulus of rupture and modulus of elasticity, hardness, density and microstructure. The shrinkage and the running qualities of the irons were also investigated. The density-temperature relation in the liquid state for each of the three irons was not affected by the degree of superheat. The strength of a bar of a given diameter was found to depend on the maximum heating temperature. In two types of iron this maximum did not occur at the same maximum heating temperature for bars of different diameter. In the third type of iron, the transverse breaking strength increased progressively up to $1,600^{\circ} \mathrm{C}$ for bars of all diameters.

The running quality of the irons investigated was not materially affected by the maximum heating temperature, but was found to be a function of the liquidus temperature. For any two irons poured at the same temperature, the running quality was found to be better in the case of the iron having the lower liquidus temperature.

The microstructure of the 1.2 -inch bars indicated that high strength is associated with relatively small graphite flakes and a pearlitic-sorbitic matrix.

Numerous investigators have shown that the strength of cast iron is a function of the amount and distribution of graphite, the optimum properties being obtained with a pearlitic or sorbitic ground mass in which the graphite is disseminated as small globular particles. Improvement in the strength of cast iron has been brought about by the control of composition, of melting and foundry practice, and by heat treatment of the castings.

This paper is a report on a preliminary study of the effect on the physical properties of three different types of iron, of heating the iron to various temperatures considerably above the melting range, and pouring at temperatures approximately $150^{\circ} \mathrm{C}$ above the liquidus. A more detailed account has been published in the Transactions of the American Foundrymen's Association, vol. 41, 449-468(1933).

For each of the irons at each of the 4 temperatures whose effect was studied, a set of 8 cylindrical transverse test bars 23 inches in 
length were cast simultaneously in a dry-sand mold. (See fig. 1.) Each set consisted of 2 bars of each of the diameters $0.75,1.2,1.5$, and 2.2 inches. The bars of 1.5-inch diameter were machined to a diameter of 1.2 inches before being tested to determine the "skin effect"; the others were tested in the as-cast condition. The crosssectional areas of the bars as tested were, therefore, in the approximate ratio of $1: 3: 9$.

The castings made in a three-part cylindrical flask were bottom poured, the bars being arranged so as to promote uniform cooling of the bars after castıng. The internal surfaces of the mold, before drying in the oven, were blackened with a mixture of water, graphite, clay, and molasses to produce castings free from "burnt-on" sand. The green-sand cope, containing the pouring basin, was placed in position just before casting.

Each charge of approximately $225 \mathrm{lb}$ of metal was melted in a high-frequency induction furnace of the tilting type in a crucible of commercial magnesia. The maximum heating temperatures were $1,400,1,500,1,600$, and $1,700^{\circ} \mathrm{C}$, respectively, for each type of iron. Temperatures of $1,600^{\circ} \mathrm{C}$ and below were measured by a platinumto-platinum 10-percent rhodium couple, whereas an optical pyrometer was used for fixing the $1,700^{\circ} \mathrm{C}$ point.

After a charge of metal had attained the desired maximum temperature the power was cut off and the metal allowed to cool to approximately $150^{\circ} \mathrm{C}$ above the liquidus temperature of the stock pig iron used in that particular charge. It should be mentioned that the liquidus temperatures of the cast metal, shown in table 1, differed from those of the stock iron used. Having attained the desired pouring temperature, the metal was poured directly from the furnace into the transverse bar mold. 


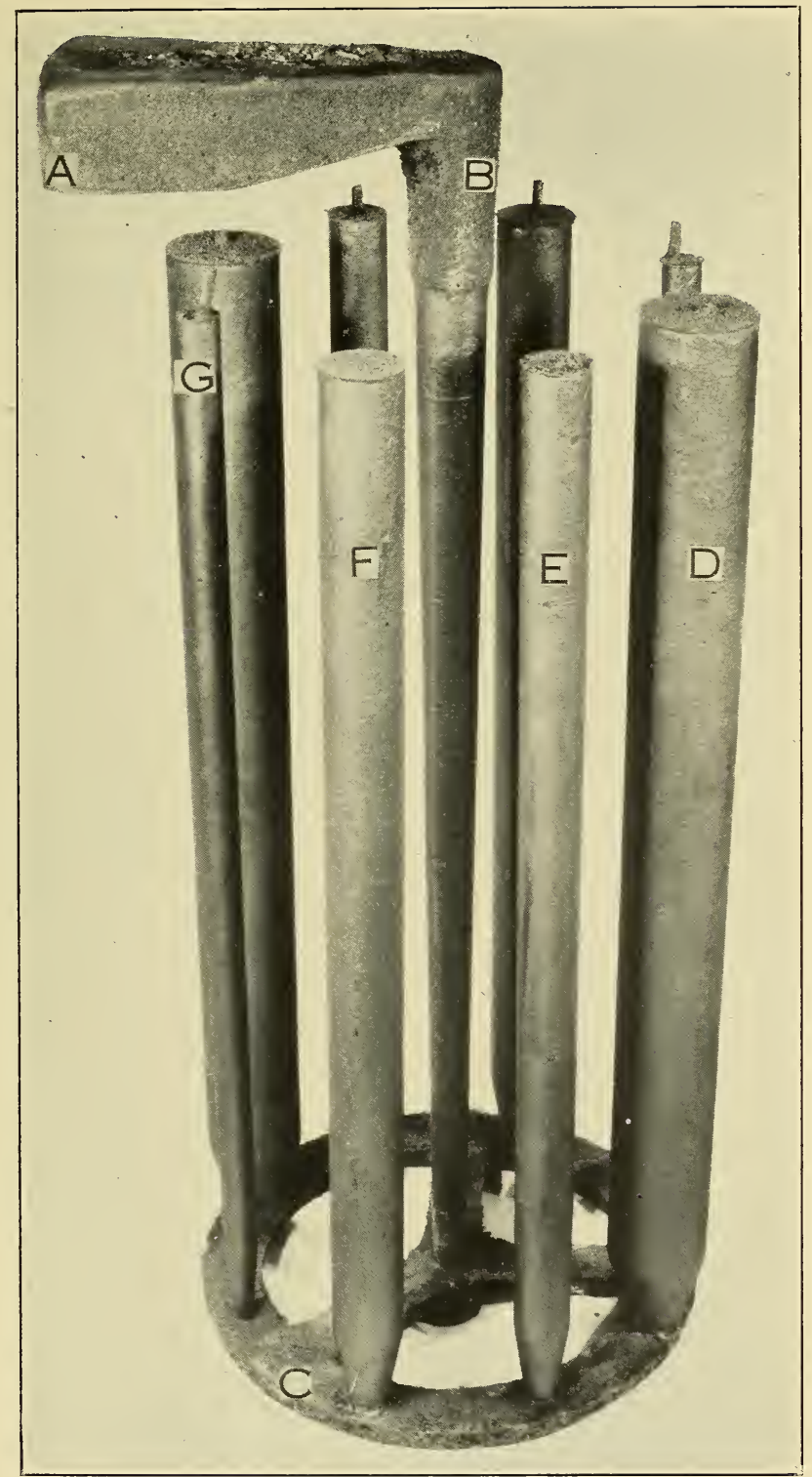

FIGURE 1.-Casting showing the method of pouring bars for transverse tests.

$A$. Pouring hasin; $B$, down gate; $C$, feeding ring; $D, 2.2$ in ${ }^{\circ}$ d diameter bar; $E, 1.2$ inch diameter bar; $F 1.5$ inch diameter bar; $G, 0.75$ inch diameter bar. 


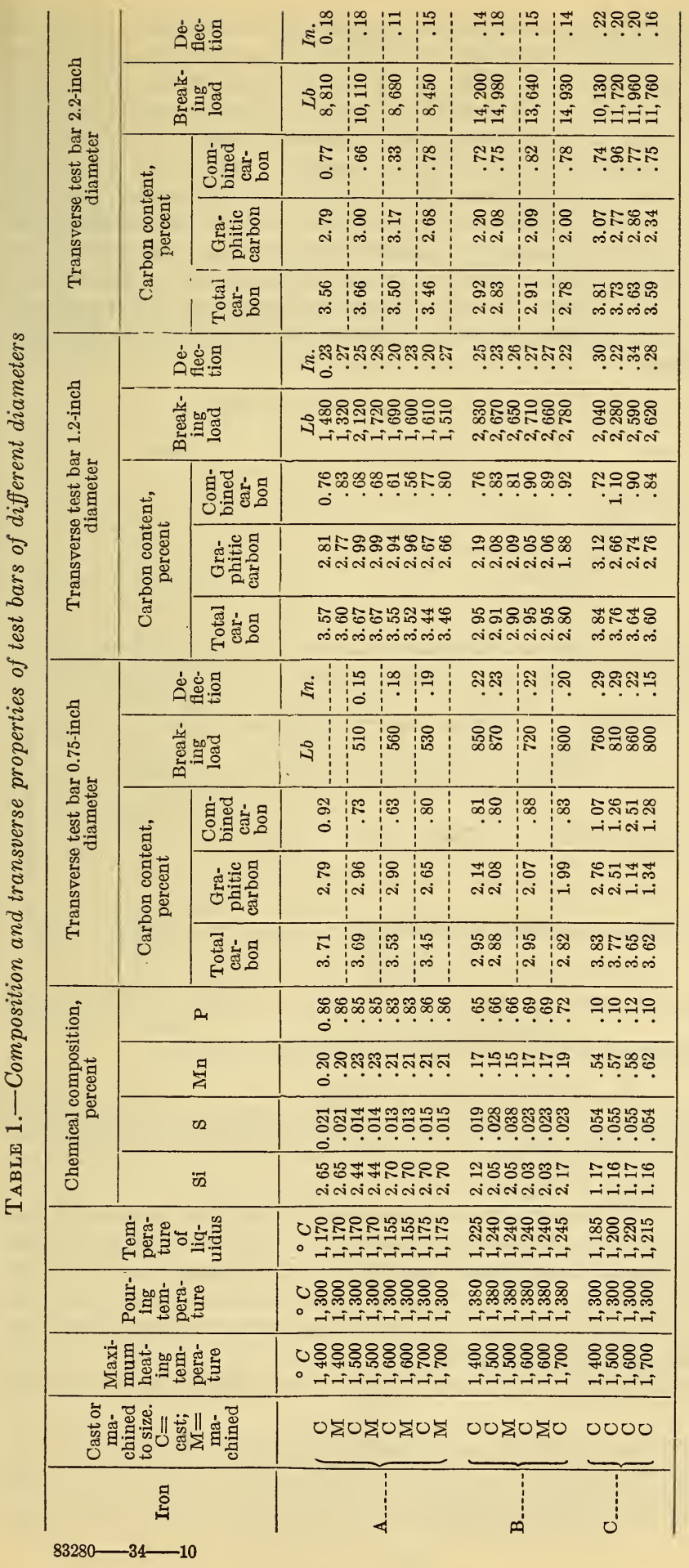


The transverse breaking load of the bars was determined with an Amsler universal testing machine of $50,000-1 b$ capacity, the load being applied so as to give a uniform rate of deflection for all bars of approximately 0.02 inch in 10 seconds. An 18-inch span was used in breaking the 1.2- and 2.2-inch bars and a 15-inch span for the 0.75inch bars. The transverse test data, together with the chemical composition and the temperature data are given in table 1. The effect of maximum heating temperature of the melt on the modulus of rupture and modulus of elasticity is shown in figure 2. However, for the purpose of brevity, data relating to specific-volume-temperature relation; linear contraction, density, hardness, and micrographs are omitted from this condensed paper. These data can be found in the original publication. ${ }^{1}$
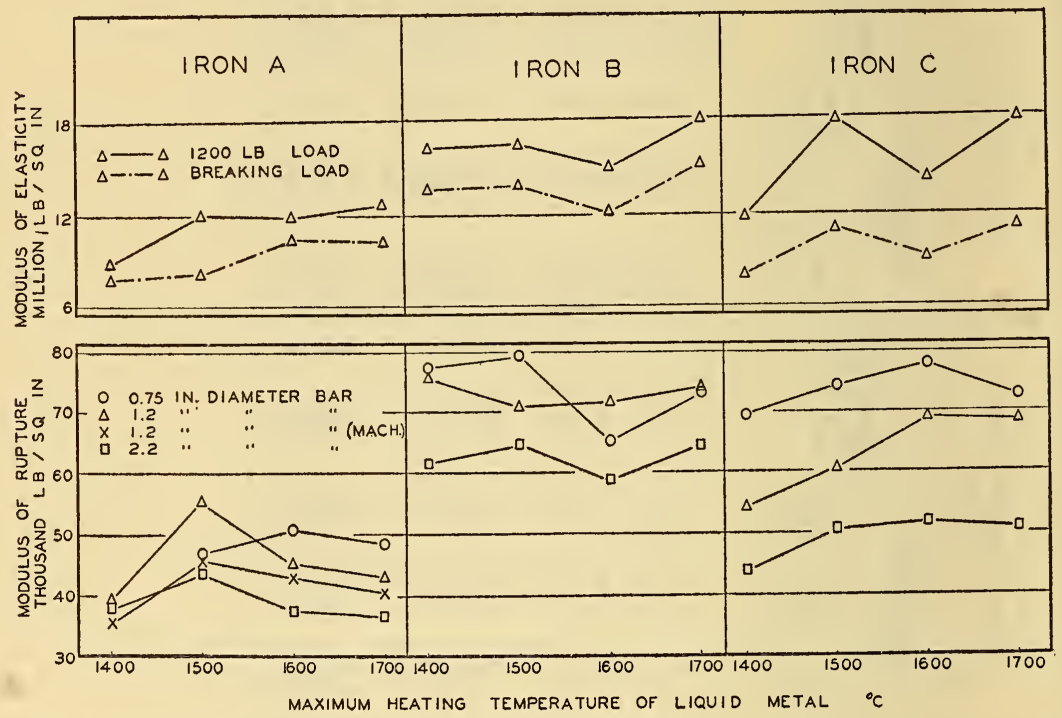

FIGURE 2.-Modulus of rupture and modulus of elasticity as affected by maximum heating temperature.

The moduli of elasticity in this figure are for the 1.2 inch diameter bar.

The running quality of each metal was determined by the method described by Saeger and Krynitsky ${ }^{2}$ which consists essentially in casting a spiral strip of small cross section in no. 00 Albany green sand. The results are plotted in figure 3.

Microstructure. Cross sections perpendicular to the length of the 1.2-inch bars of the three irons (A, B, and C) were examined microscopically. The grinding and polishing of the specimens was done according to the method of Vilella ${ }^{3}$ in order to preserve the graphite particles intact, and thus permit a comparison of the size of the graphite particles in the different irons.

The results of the investigation support the following essential conclusions:

1 C. M. Saeger, and E. J. Ash. Properties of gray cast iron as affected by casting conditions, American Foundrymen's Transactions, 41, 449-468(1933).

2 C. M. Saeger, Jr., and A. I. Krynitsky, A practical method for studying the running qualities of a metal cast in foundry molds. Trans., A.F.A., 39, 513-540(1931).

$3 \mathrm{~J}$. R. Vilella, Improved method of polishing metallographic specimens of cast iron. Metals and Alloys, 3 205(1932). 
1. The density-temperature relation in the liquid state, for each of the three irons, was not affected by the degree of superheat.

2. The strength of a bar of a given diameter was found to depend on the maximum heating temperature. In two types of iron this maximum did not occur at the same maximum heating temperature for bars of different diameter. In the third type of iron, the transverse breaking strength increased progressively up to $1,600^{\circ} \mathrm{C}$ for bars of all diameters.

3. The running quality of the irons investigated was not materially affected by the maximum heating temperature, but was found to be a function of the liquidus temperature. For any two irons, poured at the same temperature, the running quality was found to be better in the case of the iron having the lower liquidus temperature.

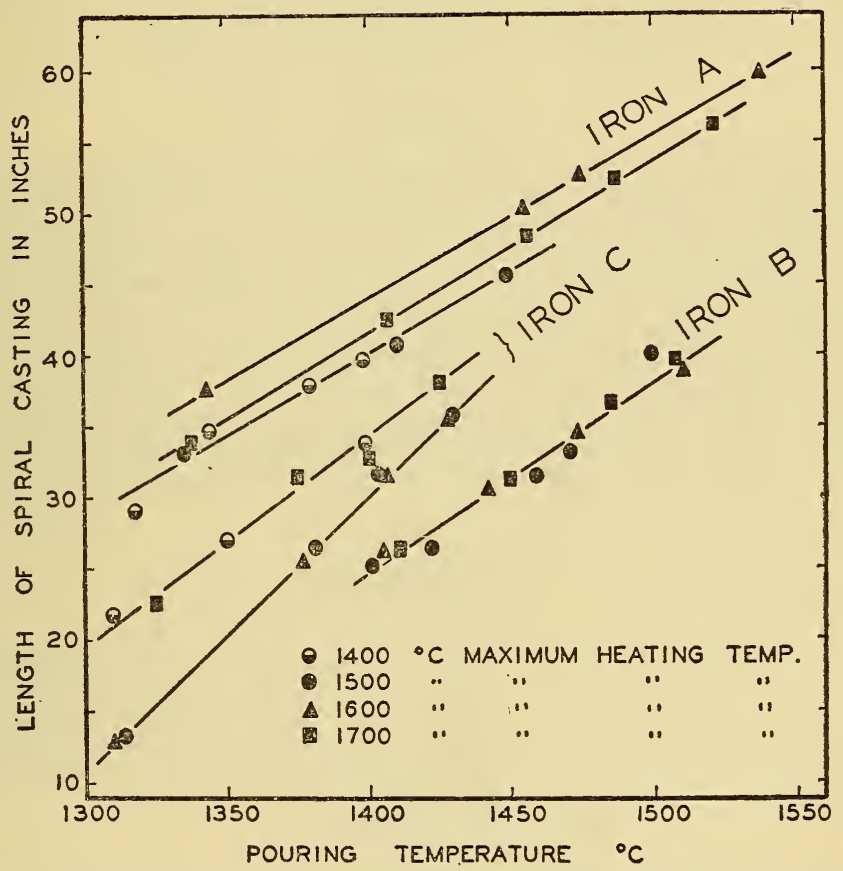

FIGURE 3.-Running quality of irons $\mathrm{A}, \mathrm{B}$, and $\mathrm{C}$, as affected by the maximum heating temperature and pouring temperature.

4. Tests on the 1.5-inch bars machined to 1.2-inch diameter indicated that the removal of the "skin" lowered the transverse breaking strength considerably. The deflection value for the machined bar was, in general, greater than the deflection of the 1.2-inch bar as cast.

5. The microstructure of the 1.2-inch bars indicated that the irons of low strength contained relatively large straight graphite flakes and coarse pearlite, whereas the irons of high strength possessed a matrix of fine pearlite or sorbite with relatively small graphite flakes disseminated through it.

6. Although a simple relationship between transverse strength and the temperature of "super-heating" prior to casting has not been established the marked improvement attained in some cases suggests the desirability of further study along this line.

Washington, August 14, 1934. 